\title{
Studi Perbandingan Total Station dan Terrestrial Laser Scanner dalam Penentuan Volume Obyek Beraturan dan Tidak Beraturan
}

\author{
Reza Fajar Maulidin, Hepi Hapsari Handayani, Yusup Hendra Perkasa \\ Jurusan Teknik Geomatika, Fakultas Teknik Sipil dan Perencanaan, Institut Teknologi Sepuluh \\ Nopember (ITS) \\ Jl. Arief Rahman Hakim, Surabaya 60111 Indonesia \\ e-mail: hapsari@geodesy.its.ac.id, yusup.h.p@solusigeospasial.co.id
}

\begin{abstract}
Abstrak-Bidang teknik sering membutuhkan penentuan volume, bahkan penentuan volume juga berpengaruh dalam bidang lain seperti bidang perekonomian serta digunakan dalam berbagai riset. Penentuan volume dalam geodesi dibantu alat ukur yang teknologinya terus berkembang. Penelitian ini dilakukan untuk mengetahui hasil penentuan volume dari dua alat ukur dengan teknologi berbeda, Total Station (TS) dan Terrestrial Laser Scanner (TLS) sebagai teknologi terbaru. Kemudian dilakukan uji ketelitian dari hasil tersebut serta beberapa analisa pada setiap proses sebelum nilai volume didapatkan. Dalam penelitian ini dilakukan penentuan volume dengan TS dan TLS pada obyek berbentuk beraturan (kontainer) sebagai obyek 1 dan tidak beraturan (bukit kapur) sebagai obyek 2. Pengukuran volume menggunakan dua metode pengukuran, yakni tachymetri untuk alat ukur TS dan Terrestrial Laser Scanning untuk alat ukur TLS. Analisa dilakukan dengan uji ketelitian koordinat Independent Check Point (ICP) dan hasil volume dari Terrestrial Laser Scanner dengan acuan hasil dari Total Station sebagai teknologi terdahulu. Berdasarkan uji statistik $t$-student kepercayaan $90 \%$ yang telah dilakukan pada ICP obyek 1 sumbu $X$ semua koordinat diterima, sedangkan sumbu $Y$ dan $Z$ terdapat masing-masing 2 koordinat yang ditolak. Pada ICP obyek 2, pada sumbu $X$ dan $Z$ terdapat masing-masing koordinat yang ditolak, sedangkan untuk sumbu $Y$ terdapat 2 koordinat yang ditolak. Terdapat 8 sampel yang ditolak dari 36 sampel atau $\mathbf{7 7 . 7 8 \%}$ sampel uji diterima. Berdasarkan uji statistik t-student yang telah dilakukan pada volume, semua nilai volume diterima. Dari hasil analisa terlihat bahwa tidak ada perbedaan yang cukup berarti/signifikan antara kedua alat ukur dalam hal ketelitian koordinat ICP maupun volume.
\end{abstract}

Kata Kunci-Independent Check Point, Terrestrial Laser Scanner, Total Station, Volume

\section{PENDAHULUAN}

$\mathrm{V}$ OLUME suatu material merupakan hal yang penting dalam banyak pekerjaan teknik. Akurasi bentuk dan estimasi volume dari material tersebut penting dalam banyak aplikasi, misalnya, studi erosi, estimasi pengambilan bahan tambang dan penilaian lahan untuk konstruksi [2]. Dalam berbagai pekerjaan Teknik, khususnya yang berhubungan dengan pembangunan, penentuan volume suatu obyek sering dilakukan. Bahkan penentuan volume yang dilakukan dalam bidang pembangunan juga berpengaruh dalam bidang lain seperti bidang perekonomian serta digunakan dalam berbagai riset dalam rangka pengembangan teknologi. Obyek yang ditentukan volumenya bisa memiliki bentuk beraturan (geometris) seperti gudang dan kontainer, maupun tidak beraturan (non geometris) seperti endapan di laut, tanah urugan (existing), dan material pertambangan.

Dalam bidang geodesi, penentuan volume dibantu dengan alat-alat ukur. Alat ukur di bidang geodesi berkembang dari awalnya dalam bentuk analog sampai ke bentuk digital. Penentuan volume dengan pengukuran metode tachymetri yang dibantu alat TS sering dilakukan dalam berbagai pekerjaan teknik. Pengukuran dilakukan dengan merekam data koordinat pada permukaan obyek yang dianggap merepresentasikan bentuk suatu obyek yang akan dihitung volumenya. Semakin tidak beraturan bentuk suatu obyek, semakin banyak pula data yang harus dikumpulkan. Munculnya TLS sebagai teknologi terbaru membuat pekerjaan perhitungan volume semakin mudah dan cepat. Dengan TLS, setiap detik bisa merekam hingga ribuan bahkan puluhan ribu titik. Perkembangan teknologi pada alat ukur digital tersebut tentunya juga diiringi dengan kelebihan maupun kekurangan masing-masing. Teknologi terkini tentunya tidak selalu unggul dalam semua aspek jika dibandingkan dengan teknologi sebelumnya. Oleh karena itu diperlukan penelitian berupa perbandingan teknologi terkini dan teknologi sebelumnya dengan beberapa aspek pengujian.

Penelitian ini dilakukan untuk mengetahui hasil penentuan volume dari 2 alat ukur dengan teknologi berbeda, Total Station (TS) dan Terrestrial Laser Scanner (TLS) sebagai teknologi terbaru. Kemudian dilakukan uji ketelitian dari hasil tersebut serta beberapa analisa pada setiap proses sebelum nilai volume didapatkan.

\section{METODOLOGI PENELITIAN}

\section{A. Data dan Peralatan}

a. Data

Data yang digunakan dalam penelitian ini adalah:

- Data Koordinat Pengukuran Tachymetri 
- Data Point Cloud Pengukuran Terrestrial Laser Scanning

b. Peralatan

Peralatan yang digunakan dalam penelitian ini adalah:

1. Alat Ukur

- Total Station Sokkia CX 102

- Terrestrial Laser Scanner Geomax Zoom300

2. Perangkat Keras (hardware)

- Personal Computer Core i3 RAM 2 GB

- Personal Computer Core i7 RAM 32 GB

3. Perangkat Lunak (software)

- Sokkia Link

- MicroSurvey CAD 2014

- AutoCAD Land Desktop 2009

- X-PAD MPS

- Microsoft Office 2013

\section{B. Metode Penelitian}

a. Lokasi Penelitian

Lokasi penelitian ini antara lain:

1. Jurusan Desain Produk ITS Surabaya (7o 16' 44" LS dan 112o 47' 47" BT) yang selnjutnya disebut lokasi 1. Obyek pada lokasi ini yakni kontainer sebagai obyek berbentuk beraturan yang selanjutnya disebut obyek 1 .

2. Bukit Jaddih Bangkalan, Madura (7o 4'59.2" LS dan $112 \mathrm{o} 45^{\prime} 39.25$ ” BT) yang selnjutnya disebut lokasi 2. Obyek pada lokasi ini yakni Bukit kapur sebagai obyek berbentuk tidak beraturan yang selanjutnya disebut obyek 2.

b. Metodologi Penelitian

Tahap-tahap penelitian terdiri dari pengumpulan data, pengolahan data serta hasil dan analisa. Untuk lebih jelasnya dapat dilihat pada Gambar 2.

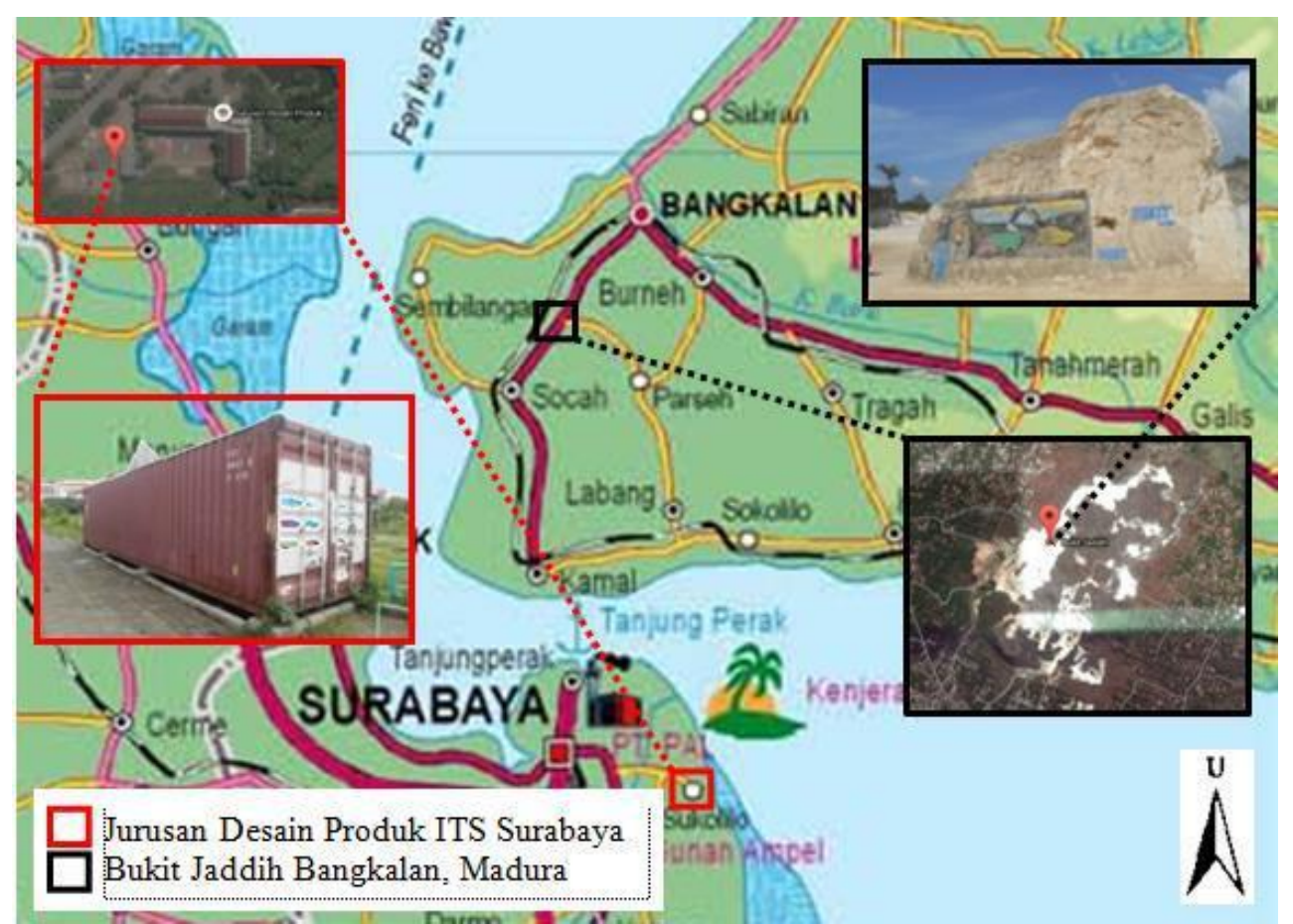

Gambar 1 Lokasi Penelitian 


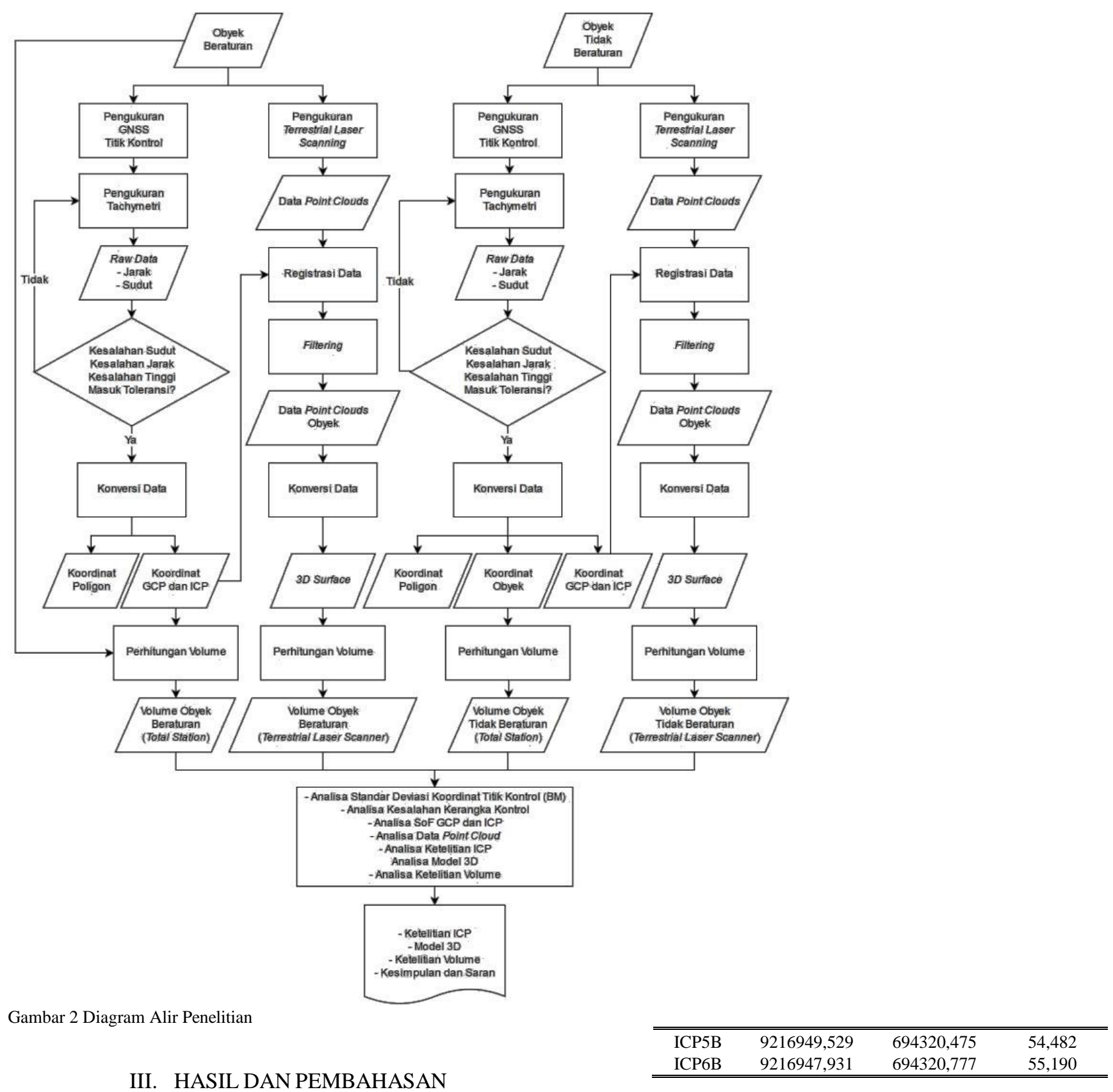

\section{A. Koordinat ICP}

Koordinat ICP yang dihasilkan dari kedua alat ukur pada kedua obyek dapat dilihat pada tabel di bawah ini:

Tabel 1

ICP dari TS

\begin{tabular}{cccc}
\hline \hline Nama & Northing $(\mathrm{m})$ & Easting $(\mathrm{m})$ & Elevasi $(\mathrm{m})$ \\
\hline \multicolumn{4}{c}{ Obyek 1 } \\
ICP1K & 9195022,749 & 698280,495 & 36,105 \\
ICP2K & 9195022,672 & 698280,514 & 33,529 \\
ICP3K & 9195022,735 & 698278,094 & 33,492 \\
ICP4K & 9195022,675 & 698279,318 & 34,859 \\
ICP5K & 9195010,509 & 698280,248 & 33,456 \\
ICP6K & 9195010,545 & 698277,828 & 35,984 \\
\multicolumn{4}{c}{ Obyek 2 } \\
ICP1B & 9216950,785 & 694317,719 & 56,533 \\
ICP2B & 9216953,606 & 694317,084 & 55,598 \\
ICP3B & 9216954,912 & 694317,982 & 55,251 \\
ICP4B & 9216953,078 & 694319,143 & 54,225 \\
\hline \hline
\end{tabular}

Tabel 2

ICP dari TLS

\begin{tabular}{cccc}
\hline \hline Nama & Northing $(\mathrm{m})$ & Easting $(\mathrm{m})$ & Elevasi $(\mathrm{m})$ \\
\hline \multicolumn{4}{c}{ Obyek 1 } \\
ICP1K & 9195022,752 & 698280,497 & 36,115 \\
ICP2K & 9195022,639 & 698280,509 & 33,526 \\
ICP3K & 9195022,733 & 698278,086 & 33,461 \\
ICP4K & 9195022,679 & 698279,305 & 34,857 \\
ICP5K & 9195010,526 & 698280,248 & 33,422 \\
ICP6K & 9195010,592 & 698277,821 & 35,988 \\
\multicolumn{4}{c}{ Obyek 2 } \\
ICP1B & 9216950,781 & 694317,752 & 56,539 \\
ICP2B & 9216953,631 & 694317,082 & 55,594 \\
ICP3B & 9216954,878 & 694317,980 & 55,257 \\
ICP4B & 9216953,071 & 694319,145 & 54,227 \\
ICP5B & 9216949,528 & 694320,475 & 54,481 \\
ICP6B & 9216947,935 & 694320,768 & 55,229 \\
\hline \hline
\end{tabular}




\section{B. Model 3D}

Berikut adalah model 3D dari masing-masing obyek:

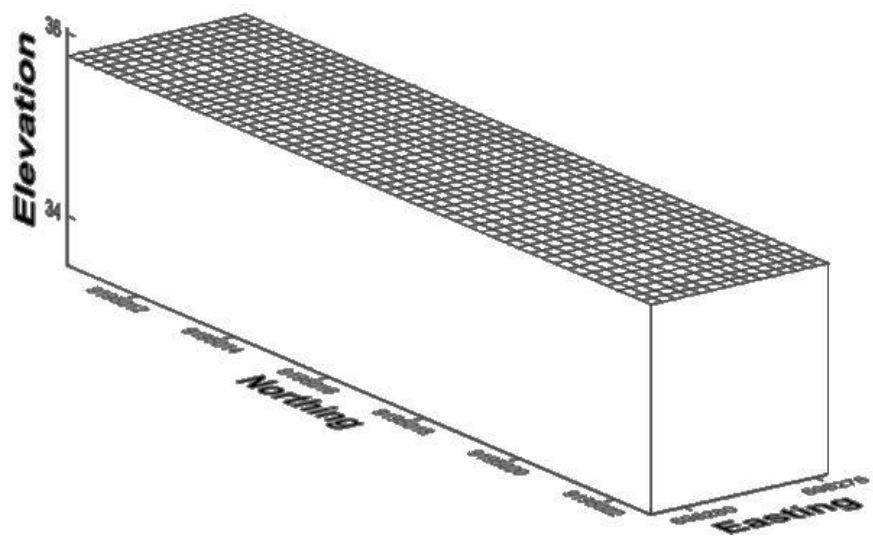

Gambar 3 Model 3D Obyek 1 dari Data Pengukuran

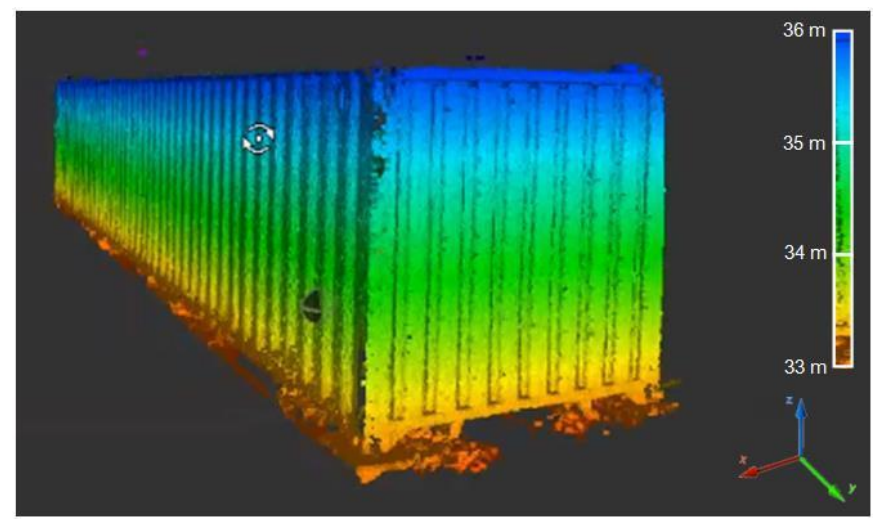

Gambar 4 Model 3D Obyek 1 dari Data Pengukuran Terrestrial Laser Scanning

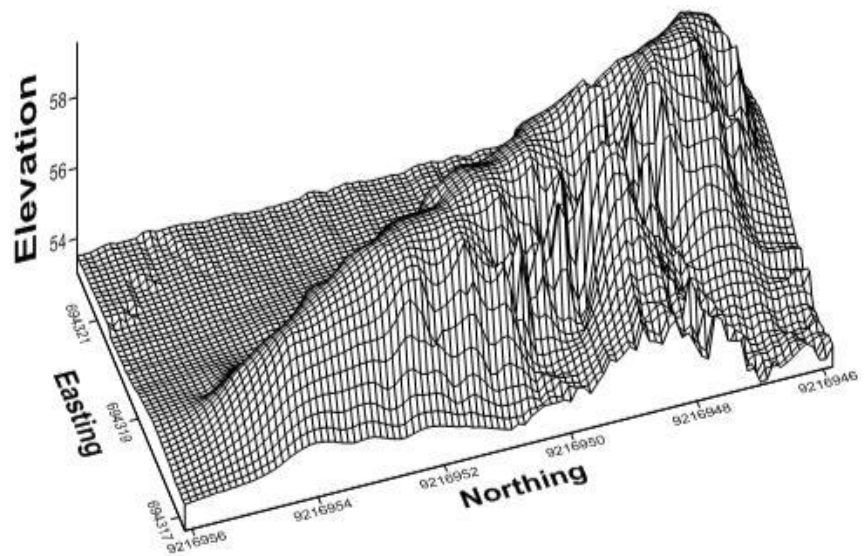

Gambar 5 Model 3D Obyek 2 dari Data Pengukuran Tachymetri

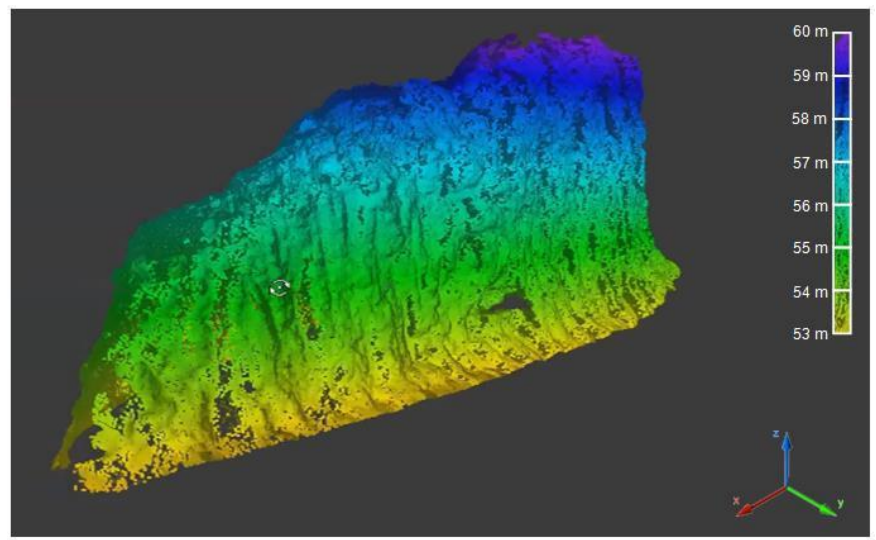

Gambar 6 Model 3D Obyek 2 dari Data Pengukuran Terrestrial Laser Scanning

\section{Volume}

Nilai volume yang didapatkan dari penelitian ini dapat dilihat pada tabel berikut:

Tabel 3

Hasil perhitungan volume

\begin{tabular}{ccc}
\hline \hline Roll Meter & Total Station & $\begin{array}{c}\text { Terrestrial Laser } \\
\text { Scanner }\end{array}$ \\
\hline \multirow{2}{*}{$75 \mathrm{~m}^{3}$} & Obyek 1 & \\
& $75,007 \mathrm{~m}^{3}$ & $74,981 \mathrm{~m}^{3}$ \\
- & Obyek 2 & \\
\hline \hline
\end{tabular}

\section{Analisa Ketelitian ICP TLS}

Uji ketelitian dilakukan untuk ICP dari pengukuran Terrestrial Laser Scanning terhadap ICP dari pengukuran dengan Total Station menggunakan uji statistik $t$ student [1]. Kepercayaan diberikan untuk uji statistik ini sebesar 90\%. Hasil dari uji statistik dapat dilihat pada tabel di bawah ini:

Tabel 4

Hasil uji ketelitian ICP TLS obyek 1

\begin{tabular}{|c|c|c|c|}
\hline Titik & Koordinat & Nilai (TLS) & Keterangan \\
\hline ICP1K & \multirow{6}{*}{ Northing (m) } & 9195022,752 & Diterima \\
\hline ICP2K & & 9195022,639 & Ditolak \\
\hline ICP3K & & 9195022,733 & Diterima \\
\hline ICP4K & & 9195022,679 & Diterima \\
\hline ICP5K & & 9195010,526 & Diterima \\
\hline ICP6K & & 9195010,592 & Ditolak \\
\hline ICP1K & \multirow{6}{*}{ Easting $(\mathrm{m})$} & 698280,497 & Diterima \\
\hline ICP2K & & 698280,509 & Diterima \\
\hline ICP3K & & 698278,086 & Diterima \\
\hline ICP4K & & 698279,305 & Diterima \\
\hline ICP5K & & 698280,248 & Diterima \\
\hline ICP6K & & 698277,821 & Diterima \\
\hline ICP1K & \multirow{6}{*}{ Elevasi (m) } & 36,115 & Diterima \\
\hline $\mathrm{ICP} 2 \mathrm{~K}$ & & 33,526 & Diterima \\
\hline ICP3K & & 33,461 & Ditolak \\
\hline ICP4K & & 34,857 & Diterima \\
\hline ICP5K & & 33,422 & Ditolak \\
\hline ICP6K & & 35,988 & Diterima \\
\hline
\end{tabular}

Tabel 5

Hasil uji ketelitian ICP TLS obyek 2

\begin{tabular}{cccc}
\hline \hline Titik & Koordinat & Nilai (TLS) & Keterangan \\
\hline ICP1B & & 9216950,781 & Diterima \\
ICP2B & Northing $(\mathrm{m})$ & 9216953,631 & Ditolak \\
ICP3B & & 9216954,878 & Ditolak \\
\hline \hline
\end{tabular}




\begin{tabular}{lccc}
\hline \hline ICP4B & & 9216953,071 & Diterima \\
ICP5B & 9216949,528 & Diterima \\
ICP6B & 9216947,935 & Diterima \\
ICP1B & & 694317,752 & Ditolak \\
ICP2B & & 694317,082 & Diterima \\
ICP3B & Easting (m) & 694317,980 & Diterima \\
ICP4B & 694319,145 & Diterima \\
ICP5B & & 694320,475 & Diterima \\
ICP6B & & 694320,768 & Diterima \\
ICP1B & & 56,539 & Diterima \\
ICP2B & & 55,594 & Diterima \\
ICP3B & \multirow{2}{*}{ Elevasi (m) } & 55,257 & Diterima \\
ICP4B & & 54,227 & Diterima \\
ICP5B & & 54,481 & Diterima \\
ICP6B & & 55,229 & Ditolak \\
\hline \hline
\end{tabular}

Berdasarkan uji statistik t-student yang telah dilakukan pada ICP obyek 1 sumbu $X$ semua koordinat diterima, sedangkan sumbu $\mathrm{Y}$ dan $\mathrm{Z}$ terdapat masing-masing 2 koordinat yang ditolak. Pada ICP obyek 2, pada sumbu X dan $\mathrm{Z}$ terdapat masing-masing 1 koordinat yang ditolak, sedangkan untuk sumbu Y terdapat 2 koordinat yang ditolak.

E. Analisa Model 3D

Tabel 6

Analisa Model 3D

\begin{tabular}{|c|c|c|}
\hline & Total Station & Terrestrial LaserScanning \\
\hline $\begin{array}{l}\text { Bentuk } \\
\text { umum }\end{array}$ & Permukaan tiga dimensi & Kumpulan titik \\
\hline $\begin{array}{l}\text { Detail } \\
\text { bentuk }\end{array}$ & Kurang detail & Sangat detail \\
\hline & & - Berdasarkan ketinggian \\
\hline Pilihan & - Berdasarkan ketinggian & - Berdasarkan jarak \\
\hline warna & - Hitam putih (wireframe) & $\begin{array}{l}\text { - Berdasarkan intensitas } \\
\text { - Warna asli obyek }\end{array}$ \\
\hline $\begin{array}{l}\text { Penghalusan } \\
\text { bentuk }\end{array}$ & Otomatis & Melalui proses meshing \\
\hline Bobot & - Obyek 1: $52 \mathrm{~KB}$ & - Obyek 1: 145 KB \\
\hline model & - Obyek 2: $66 \mathrm{~KB}$ & - Obyek 2: $160 \mathrm{~KB}$ \\
\hline
\end{tabular}

F. Analisa Ketelitian Perhitungan Volume dengan TLS

Volume yang didapatkan dibandingkan dengan uji statistik $t$ student dengan kepercayaan $90 \%$. Untuk obyek 1, nilai volume yang menjadi referensi adalah dari pengukuran panjang, lebar, dan tinggi dengan menggunakan roll meter. Sedangkan untuk obyek 2, yang menjadi referensi adalah pengukuran dengan menggunakan Total Station. Berikut ini adalah hasil uji statistik pada volume:

Tabel 7

Hasil uji statistik ketelitian hasil volume dengan TLS

\begin{tabular}{cccc}
\hline \hline Referensi & Vol. Referensi & Volume (TLS) & Keterangan \\
\hline Roll meter & $75 \mathrm{~m}^{3}$ & Obyek 1 & \\
& \multicolumn{2}{c}{ Obyek 2 } & Diterima \\
TS & $89,117 \mathrm{~m}^{3}$ & $89,142 \mathrm{~m}^{3}$ & Diterima \\
\hline \hline
\end{tabular}

Hasil uji statistik menunjukkan ketelitian dari nilai volume hasil dari pengukuran Terrestrial Laser Scanning diterima atau masuk toleransi pada kedua obyek.

\section{PENUTUP}

\section{A. Kesimpulan}

1. Berdasarkan perhitungan volume yang telah dilakukan pada obyek 1, dari pengukuran dimensi didapatkan nilai volume sebesar75 $\mathrm{m}^{3}$, dari alat ukur TS didapatkan nilai volume sebesar75.007 $\mathrm{m}^{3}$, dan dari alat ukur TLS didapatkan nilai volume sebesar74.981 $\mathrm{m}^{3}$. Pada obyek 2 dari alat ukur TS didapatkan nilai volume sebesar $89.117 \mathrm{~m}^{3}$, dan dari alat ukur TLS didapatkan nilai volume sebesar $89.142 \mathrm{~m}^{3}$. Perbedaan nilai volume satu sama lain dari kedua alat ukur pada kedua obyek tidak signifikan.

2. Berdasarkan uji statistik $t$-student yang telah dilakukan pada ketelitian ICP dari pengukuran TLS terdapat 8 sampel yang ditolak dari 36 sampel atau $77.78 \%$ sampel berada di dalam rentang uji statistik. Hal ini menunjukkan ketelitian volume diterima atau masuk toleransi uji statistik pada kedua obyek jika dibandingkan dengan TS sebagai teknologi terdahulu.

3. Berdasarkan uji statistik t-student yang telah dilakukan pada ketelitian volume semua nilai volume hasil dari pengukuran TLS berada di dalam rentang uji statistik. Hal ini menunjukkan ketelitian volume diterima atau masuk toleransi uji statistik pada kedua obyek jika dibandingkan dengan TS sebagai teknologi terdahulu.

\section{B. Saran}

1. Pengambilan data menggunakan Terrestrial Laser Scanner sebaiknya menggunakan sudut horisontal yang sesuai untuk meringankan beban data dan supaya tidak banyak data yang dihapus dalam proses filtering.

2. Terrestrial Laser Scanner lebih tepat untuk pekerjaan dalam skala besar seperti bidang pertambangan.

\section{UCAPAN TERIMA KASIH}

Penulis mengucapkan terima kasih kepada Ibu Hepi Hapsari Handayani, S.T., M.Sc selaku pembimbing, serta PT. Sistem Solusi Geospasial yang telah memberikan dukungan dalam penelitian ini melalui pinjaman alat ukur terrestrial laser scanner beserta ilmu pengolahan datanya.

\section{DAFTAR PUSTAKA}

[1] Ghilani, C. D., \& Wolf, P. R. 2006. Adjustment Computation: Spatial Data Analysis (4th ed.). Hoboken: John Wiley \& Sons.

[2] Yakara, M. and Yilmazb, H.M. 2008.Using In Volume Computing Of Digital Close Range Photogrammetry. The International Archives of the Photogrammetry, Remote Sensing and Spatial Information Sciences. Vol. XXXVII. Part B3b. Beijing. 